\title{
Aa. Vv., «Bulletin des Amis d'André Gide»
}

\section{Emanuele Kanceff}

\section{(2) OpenEdition}

\section{Journals}

\section{Edizione digitale}

URL: http://journals.openedition.org/studifrancesi/35102

DOI: 10.4000/studifrancesi.35102

ISSN: 2427-5856

\section{Editore}

Rosenberg \& Sellier

\section{Edizione cartacea}

Data di pubblicazione: 1 novembre 2005

Paginazione: 446

ISSN: 0039-2944

\section{Notizia bibliografica digitale}

Emanuele Kanceff, «Aa. Vv., «Bulletin des Amis d'André Gide»», Studi Francesi [Online], 146 (XLIX | II) | 2005, online dal 30 novembre 2015, consultato il 18 avril 2021. URL: http://journals.openedition.org/ studifrancesi/35102 ; DOI: https://doi.org/10.4000/studifrancesi.35102

Questo documento è stato generato automaticamente il 18 avril 2021.

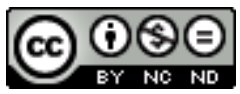

Studi Francesi è distribuita con Licenza Creative Commons Attribuzione - Non commerciale - Non opere derivate 4.0 Internazionale. 


\title{
Aa. Vv., «Bulletin des Amis d'André Gide»
}

\author{
Emanuele Kanceff
}

\section{NOTIZIA}

«Bulletin des Amis d'André Gide», trente-sixième année, vol. XXXII, n. 143-144, juilletoctobre 2004, pp. 273-436.

1 La storica rivista dell'Associazione degli Amici di André Gide, pur conservando tutte le caratteristiche cui siamo abituati ed affezionati, sembra pervasa da un desiderio di novità. Questo si traduce essenzialmente in una marcata preferenza del documento autentico e nella presenza massiccia di inediti (il che non è in contraddizione con l'immagine storica della rivista). Diamo qui di seguito il contenuto del fascicolo di luglio-ottobre 2004, numero doppio 143-144: André Gide et Présence Africaine un texte peu connu, présenté par Meadow DIBBLE-FIENG. - Anton ALBLAS, Gide devant son cahier: la pratique (II). - Alain GOULET, Gide et la Sixtine de Gourmont. - Claude FOUCART, André Gide et Friedrich Gundolf: les affinités souterraines. - Rouen, 19 juin 2004: L'Aaag en visite, par Henri HEINEMANN. - Sandra TRAVERS DE FAULTRIER, Le peuple juge du peuple. - Jean-François MINOT, Gide, fils spirituel de Flaubert. - Une campagne éditoriale d'André Gide 1918-1923: Lettres à Édouard Verbeke présentées par Pierre MASSON. - Robert LEVESQUE, Journal inédit. Suite (décembre 1944-janvier 1945). - Les Dossiers des livres d'André Gide: Voyage au Congo (Marc CHADOURNE), Journal (Henry BIDOU, André THÉRIVE), Retour de l'U.R.S.S. (Denis DE ROUGEMONT, Brice PARAIN). - Lectures: Fr. Vielé-Griffin - H. GHÉON, Correspondance [par Pierre LACHASSE]. Chronique bibliographique. 